\title{
Production of Hydrolyzed Red Ginseng Residue and Its Application to Lactic Acid Bacteria Cultivation
}

\author{
Dong Chung Kim ${ }^{1,2}$ and Man-Jin In ${ }^{1,2^{*}}$ \\ 'Department of Human Nutrition and Food Science, Chungwoon University, Hongseong 350-701, Korea \\ ${ }^{2}$ International Institute of Bio and Health Science, Chungwoon University, Hongseong 350-701, Korea
}

Enzymatic treatment conditions for red ginseng residue (RGR) were investigated to apply RGR as a microbial medium. Polysaccharide hydrolyase and protease were screened to obtain high solid and carbohydrate yields, and a good degree of carbohydrate hydrolysis. The optimal dosage and reaction time for Viscozyme, the chosen polysaccharide hydrolyase, were found to be $1.0 \%(\mathrm{w} / \mathrm{w})$ and $3 \mathrm{~h}$, respectively. Of the tested proteases, Flavourzyme, whose optimal dosage was $0.5 \%(\mathrm{w} / \mathrm{w})$, was selected. Co-treatment with the optimal dosages of Flavourzyme and Viscozyme increased solid yield, carbohydrate yield, and degree of carbohydrate hydrolysis by $76 \%, 65 \%$, and $1,865 \%$, respectively, over levels in non-treated RGR. The culture characteristics of Leuconostoc mesenteroides strain KACC 91459P grown in enzymatically hydrolyzed red ginseng residue (ERGR) and RGR suspensions were compared. After cultivation for $6 \mathrm{~h}$, the viable cell counts of both cell suspensions rapidly increased to $1.3 \times 10^{9}$ colony-forming units (CFU)/g. Moreover, while the viable cell population drastically decreased to $2.4 \times 10^{6}$ $\mathrm{CFU} / \mathrm{g}$ for cells grown in RGR medium, it was maintained in cells fermented in ERGR medium for $24 \mathrm{~h}$.

Keywords: Enzymatic hydrolysis, Lactic acid bacteria, Microbial medium, Red ginseng residue

\section{INTRODUCTION}

In Asia, ginseng (Panax ginseng C. A. Meyer) has long been used as a traditional herbal medicine for the prevention and cure of various diseases. Functional compounds in ginseng showing biological activity include ginsenosides (saponin), acidic polysaccharides, peptides, polyacetylenes, alkaloids, and phenolic compounds [1]. To extend its storage period and enhance it's efficacy, raw ginseng is often processed into white and red ginseng products in the Korean ginseng industry. Red ginseng is known to be more pharmaceutically active than white ginseng because of its higher content of specific ginsenosides such as $\mathrm{Rg}_{3}, \mathrm{Rh}_{2}$, and $\mathrm{Rb}_{2}$ [2,3]. Among the processed products derived from red ginseng, the aqueous extract of red ginseng is the most important due to its higher applicability in the food industry. The water-soluble components, which mainly consist of ginsenosides and acidic polysaccharides, are recovered by direct extraction from red ginseng in hot water or a mixture of water and ethanol [4,5]. The water-insoluble part of red ginseng, red ginseng residue (RGR), is the by-product of this extraction process and is generally discarded as waste, even though it contains components with biological activities [6]. In previous studies, RGR has been utilized as a foodstuff and culture medium additive, and applied to the recovery of bioactive compounds such as acidic polysaccharides and lipid-soluble components [7-9].

Recently, microbial methods have been used in the (c) This is an Open Access article distributed under the terms of the Creative Commons Attribution Non-Commercial License (http://creativecommons.org/licenses/by-nc/3.0/) which permits unrestricted non-commercial use, distribution, and reproduction in any medium, provided the original work is properly cited.
Received 23 Jul. 2010, Revised 31 Aug. 2010, Accepted 11 Oct. 2010

"Corresponding author

E-mail: manjin@chungwoon.ac.kr

Tel: +82-41-630-3278, Fax: +82-41-632-3278 
transformation of medicinal herbs. In particular, a great deal of attention has focused on the fermentation of ginseng. Fermentation of red ginseng by intestinal microorganisms transforms ginsenosides such as $\mathrm{Rb}_{1}, \mathrm{Rb}_{2}, \mathrm{Rc}$, and $\mathrm{Rd}$ into readily absorbable low-molecular-weight active products such as compound $\mathrm{K}$, which is active against cancer and diabetes, and in immune stimulation [10-12]. Lactic acid bacteria, which are very safe but fastidious microorganisms with complicated nutritional requirements, have been highly applied in the production of fermented red ginseng. For efficient cultivation of lactic acid bacteria during ginseng fermentation, partial enzymatic degradation of ginseng constituents and subsequent use of the resulting hydrolysates as nutritional sources is preferable to supplementation with additional nutrients. Ceremix, a mixture of commercial polysaccharide hydrolases, was reported to be a suitable enzyme in the extraction of total saccharides from ginseng leaves, stems, and roots for use as a pretreatment for the production of fermented ginseng [13]. From an economical viewpoint, enzymatic treatment of ginseng residue may be preferable to similar treatment of whole ginseng roots for the supplementation of nutrients. However, to our knowledge, the enzymatic hydrolysis of RGR and use of the resulting hydrolysate have not before been studied, although a few reports have described the enzyme treatment of RGR for the purpose of extracting acidic polysaccharides [8].

In an attempt to apply RGR as a stand-alone microbial medium without any added nutrients, we explored the conditions for extracting total sugars from RGR through treatment with polysaccharide hydrolases and proteases, and compared the characteristics of lactic acid bacteria cultured in RGR and enzymatically hydrolyzed red ginseng residue (ERGR).

\section{MATERIALS AND METHODS}

\section{Materials}

RGR from ethanol extraction was provided by Greenbio Co. (Icheon, Korea) and ground to a particle size of less than $500 \mu \mathrm{m}$. Commercial polysaccharide hydrolases (Celluclast, Ceremix, Fructozyme, Pectinex, Ultraflo, and Viscozyme) and proteases (Alcalase, Flavourzyme, Kojizyme, Nutrase, and Protamex) were purchased from Novozyme (Bagsvaerd, Denmark). Leuconostoc mesenteroides (L. mesenteroides) KACC 91459P was obtained from the Korean Agricultural Culture Collection (Suwon, Korea) [14]. All other reagents were of analytical grade.

\section{Enzyme treatments}

RGR powder was suspended in distilled water at a concentration of $10 \%(\mathrm{w} / \mathrm{v})$. After its $\mathrm{pH}$ was adjusted with $1 \mathrm{~N} \mathrm{NaOH}$ or $\mathrm{HCl}$ such that it was optimal for each polysaccharide hydrolase or protease, the resulting RGR suspension was mixed with enzymes $(1 \%[\mathrm{w} / \mathrm{w}]$ [based on the RGR powder weight]) and incubated at $50^{\circ} \mathrm{C}$ for $3 \mathrm{~h}$ in a shaking water bath. After enzymatic hydrolysis, the suspensions were boiled for $20 \mathrm{~min}$ and centrifuged at $2,000 \times \mathrm{g}$ for $5 \mathrm{~min}$. The resulting supernatant was analyzed for solid and carbohydrate contents.

\section{Microbial cultivation}

The RGR suspension was simultaneously incubated with Viscozyme and Flavourzyme for $3 \mathrm{~h}$ and then autoclaved at $121^{\circ} \mathrm{C}$ for $15 \mathrm{~min}$. The resulting ERGR suspension (without any added nutrients) was used as a lactic acid bacteria culture medium. L. mesenteroides KACC 91459P was precultured in Lactobacilli MRS broth (Difco Laboratories, Detroit, MI, USA) at $30^{\circ} \mathrm{C}$ for $15 \mathrm{~h}$ on a rotary shaker with agitation $(150 \mathrm{rpm})$. Cells were harvested from the preculture broth by centrifugation at $3,000 \times \mathrm{g}$ for $15 \mathrm{~min}$ and washed twice with physiological saline. The washed pellets were suspended in a volume of physiological saline equivalent to that of the preculture broth. ERGR medium was then inoculated with washed L. mesenteroides KACC 91459P cell suspension $(5 \%[\mathrm{v} / \mathrm{v}])$. The cells were then cultured for $24 \mathrm{~h}$ under the same conditions used for the preculture. The $\mathrm{pH}$ of the fermented ERGR broth was measured using a 720P pH meter (Istek, Seoul, Korea). Titratable acidity was determined by titrating $5 \mathrm{~g}$ of the sample with $0.01 \mathrm{~N} \mathrm{NaOH}$ using phenolphthalein as an indicator. Results were expressed as percentages of lactic acid. L. mesenteroides KACC 91459P growth was assessed by counting viable cells after plating the culture on MRS agar plates. The plates were incubated at $30^{\circ} \mathrm{C}$ for $36 \mathrm{~h}$, and the culture density was estimated in terms of colony-forming units (CFU).

\section{Analysis}

RGR moisture, ash, crude lipid, and crude protein contents were determined according to the recommended protocols in the Korean Food Code (Korea Food and Drug Administration) [15]. The carbohydrate content was calculated by subtracting the moisture, ash, crude lipid, and crude protein weights from the total weight of the sample. Total solid, total carbohydrate, and reducing sugar contents in the polysaccharide hydrolase- and/or protein hydrolase-treated RGR were respectively deter- 
mined using a PR-32 $\alpha$ refractometer (Atago Co., Tokyo, Japan) using the phenol-sulfuric acid method [16] and by the DNS method [17] using glucose as a standard. Solid yield (SY), carbohydrate yield (CY), and degree of carbohydrate hydrolysis $(\mathrm{DCH})$ were then calculated using the following equations [18-20]:

SY $(\%)=($ total weight of solid in the ERGR supernatant/total RGR weight) $\times 100$

CY $(\%)=($ total weight of carbohydrate in the ERGR supernatant/total RGR carbohydrate weight) $\times 100$

DCH $(\%)=$ (total weight of reducing sugar in the ERGR supernatant/total RGR carbohydrate weight) $\times 100$

The presented data for SY, CY, and DCH represent the means and standard deviation of values measured at least in triplicate.

\section{RESULTS AND DISCUSSION}

\section{Enzyme screening}

To screen enzymes for use in hydrolyzing RGR, the approximate chemical composition of RGR was determined. Its total carbohydrate and crude protein contents were $70.24 \%$ and $18.20 \%$, respectively (Table 1 ). These results are very similar to those obtained for red ginseng tail and its extraction residues [7]. Composition data suggested that degradation of the major water-insoluble components (carbohydrate and protein) to readily usable low-molecular-weight products would be necessary for the growth of microorganisms on RGR. These are effective methods for generating carbon and nitrogen sources for use as growth nutrients. To choose the suitable polysaccharide-hydrolyzing enzyme, the RGR suspension was treated with commercially available carbohydratases (concentration $1 \%$ concentration on a solid weight basis). Of the tested polysaccharide hydrolases, Viscozyme (a mixture of $\beta$-glucanase, cellulase, hemicellulase, xylanase, and arabanase) and Ceremix (a mixture of $\beta$-glucanase, cellulase, pentosanase, proteinase, and $\alpha$-amylase) gave the highest CY $(46.9 \%)$ and SY (48.0\%), respectively. The differences in yields between these two enzymes were not significant (Table 2).

Table 1. Approximate chemical composition of red ginseng residue

\begin{tabular}{lc}
\hline Components & Content (\%) \\
\hline Carbohydrate & 70.24 \\
Crude protein & 18.20 \\
Crude lipid & 1.22 \\
Ash & 5.89 \\
Water & 4.45 \\
\hline
\end{tabular}

Table 2. Effects of various enzyme treatments on the solubilization of red ginseng residue

\begin{tabular}{lccc}
\hline \multicolumn{1}{c}{ Enzymes } & Solid yield & Carbohydrate yield & DH for carbohydrate \\
\hline Celluclast & $38.7 \pm 3.1$ & $36.1 \pm 6.1$ & $7.5 \pm 1.5$ \\
Ceremix & $48.0 \pm 1.0$ & $43.3 \pm 5.7$ & $17.0 \pm 3.2$ \\
Fructozyme & $34.7 \pm 4.6$ & $31.3 \pm 5.7$ & $6.3 \pm 1.7$ \\
Pectinex & $36.7 \pm 3.5$ & $34.9 \pm 5.7$ & $14.5 \pm 2.7$ \\
Ultraflo & $36.0 \pm 2.0$ & $32.6 \pm 7.4$ & $3.6 \pm 1.1$ \\
Viscozyme & $45.7 \pm 3.1$ & $46.9 \pm 8.7$ & $28.4 \pm 3.0$ \\
Alcalase & $46.5 \pm 0.5$ & $50.3 \pm 3.3$ & $10.4 \pm 1.3$ \\
Flavourzyme & $46.0 \pm 4.0$ & $59.7 \pm 0.4$ & $22.7 \pm 2.6$ \\
Kojizyme & $41.0 \pm 1.0$ & $47.2 \pm 1.6$ & $20.0 \pm 2.6$ \\
Nutrase & $46.5 \pm 3.5$ & $54.5 \pm 2.5$ & $6.6 \pm 1.1$ \\
Protamex & $48.0 \pm 2.0$ & $63.1 \pm 1.2$ & $8.1 \pm 1.6$ \\
Control & $31.0 \pm 1.7$ & $32.6 \pm 7.4$ & $2.3 \pm 0.4$ \\
\hline
\end{tabular}

Values are presented as percentage.

$\mathrm{DH}$, degree of hydrolysis.

However, the value of DCH - the ratio of water-soluble reducing sugar to total carbohydrate content-increased from $2.3 \%$ (non-treated control) to $28.4 \%$ following treatment with Viscozyme, but to only $17.0 \%$ following treatment with Ceremix. Despite Ceremix having been reported to be effective for the extraction of total saccharides from ginseng leaves, stems, and roots [13], we concluded that Viscozyme was more suitable in our experiments using RGR as the substrate. These results indicate that the polysaccharide hydrolases degraded the RGR polysaccharides, which in turn increased the solubility of the polysaccharides, in accordance with the results of previous studies using vegetable materials as substrates $[18,19]$. A study also reported that a protease treatment improved the total solid and protein recovery from soymilk residue by hydrolyzing the protein part of peptidoglycan in plant cell walls and thereby increasing the solubility of both polysaccharides and proteins [19]. Notably, Flavourzyme, an exopeptidase, yielded the highest DCH $(22.7 \%)$ of the tested proteases (Table 2). This enzyme had been also selected for the production of yeast extract [20] and heme-enriched peptide [21] via the enzymatic hydrolysis of yeast cells and hemoglobin, respectively.

\section{Enzymatic hydrolysis of red ginseng residue}

To optimize the enzyme treatment conditions, the RGR suspension was treated with different concentrations of Viscozyme ( $0 \%$ to $5.0 \%$ on a solid weight basis). Treatment for $3 \mathrm{~h}$ showed that SY, CY, and DCH strongly depended on a Viscozyme concentration in the range of $0 \%$ to $1 \%$ (Fig. 1A). Treatment with $1 \%$ Vis- 

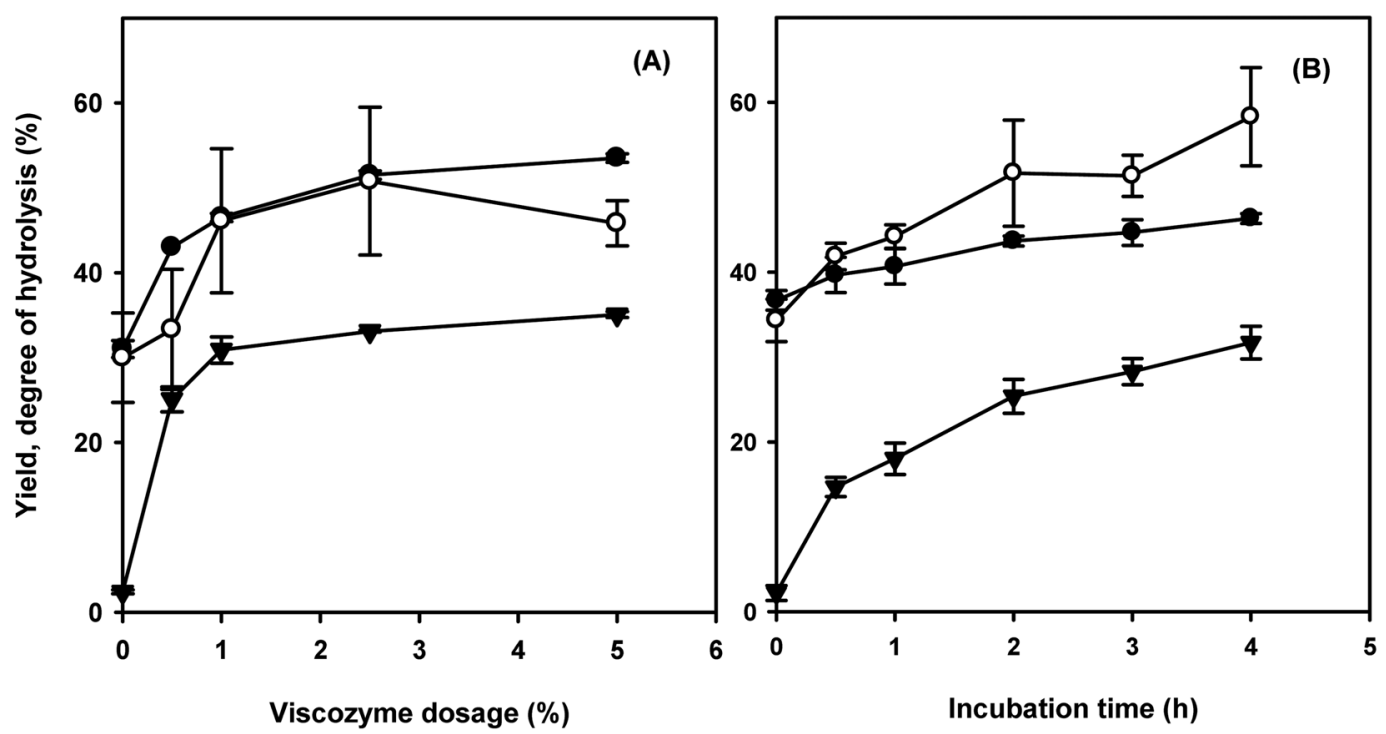

Fig. 1. Effects of Viscozyme dosage (A) and reaction time (B) on solid yield $(\bullet)$, carbohydrate yield ( $(0)$, and degree of carbohydrate hydrolysis $(\boldsymbol{\nabla})$. Reaction conditions $(A)$ : substrate, $10 \%$ red ginseng residue (RGR) suspension; temperature, $50^{\circ} \mathrm{C}$; $\mathrm{pH}, 5.0$; reaction time, $3 \mathrm{~h}$. Reaction conditions (B): substrate, $10 \%$ RGR suspension; enzyme dosage, $1 \%$; temperature, $50^{\circ} \mathrm{C} ; \mathrm{pH}, 5.0$.

cozyme increased SY, CY, and DCH by $50 \%, 54 \%$, and $1,187 \%$, respectively (versus non-treated control). The optimal dosage of Viscozyme was found to be $1.0 \%$. Time-course analysis of SY, CY, and DCH following treatment with $1.0 \%$ Viscozyme revealed that $\mathrm{CY}$ and $\mathrm{DCH}$ increased significantly with the increasing reaction time, while SY increased only slightly (Fig. 1B). CY, DCH, and SY increased by $50 \%, 1,186 \%$, and $22 \%$, respectively, after hydrolysis for $3 \mathrm{~h}$. The marked enhancement of DCH was due to the enzymatic hydrolysis of glycoside bonds in polysaccharides and the release of soluble low-molecular-weight carbohydrates with reducing power, as occurs during the hydrolysis of soymilk residue [18].

As with Viscozyme, the effects of Flavourzyme dosage and reaction time on SY, CY, and DCH were determined. The effects of the Flavourzyme treatment followed a similar pattern to those of the Viscozyme treatment (data not shown). SY, CY, and DCH increased by $52 \%, 49 \%$, and $731 \%$, respectively, following treatment with $0.5 \%$ Flavourzyme (vs. non-treated control). Noticeably, DCH with Viscozyme was higher than with Flavourzyme. The optimal dosage and reaction time for Flavourzyme were found to be $0.5 \%$ and $1 \mathrm{~h}$, respectively.

To identify the optimal enzyme combination, the RGR suspension was treated with different combinations of polysaccharide hydrolases and proteases. Hydrolysis was performed using the combination of Viscozyme and Flavourzyme. Values of SY, CY, and DCH follow- ing treatment with $0.5 \%$ Flavourzyme and various concentrations of Viscozyme, as well as with each enzyme alone, are shown in Table 3. Co-treatment with the optimized dosages of Flavourzyme $(0.5 \%)$ and Viscozyme $(1.0 \%)$ significantly increased the values of SY, CY, and $\mathrm{DCH}$ to $76 \%(26 \% \rightarrow 46 \%), 65 \%(43.76 \% \rightarrow 72.27 \%)$, and $1,865 \%(1.93 \% \rightarrow 37.93 \%)$, respectively (vs. nontreated control). This increase in hydrolysis achieved through treatment with two different enzymes was very similar to those reported in studies on the hydrolysis of hemoglobin [21] and chlorella [22], and the extraction of astaxanthin from Haematococcus pluvialis [23]. As shown in both the present study and previous investigations, the use of multiple enzymes is a helpful strategy

Table 3. Effects of enzymes co-treatments on the solubilization of red ginseng residue ${ }^{1)}$

\begin{tabular}{|c|c|c|c|c|}
\hline \multicolumn{2}{|c|}{ Enzyme dosage } & \multirow{2}{*}{ Solid yield } & \multirow{2}{*}{$\begin{array}{c}\text { Carbohydrate } \\
\text { yield }\end{array}$} & \multirow{2}{*}{$\begin{array}{c}\text { DH for } \\
\text { carbohydrate }\end{array}$} \\
\hline Flavourzyme & Viscozyme & & & \\
\hline 0 & 0 & 26 & 43.76 & 1.93 \\
\hline 0 & 1.0 & 40 & 66.23 & 28.16 \\
\hline 0.5 & 0 & 38 & 69.76 & 17.85 \\
\hline 0.5 & 1.0 & 46 & 72.27 & 37.93 \\
\hline 0.5 & 2.0 & 48 & 72.72 & 39.55 \\
\hline 0.5 & 5.0 & 50 & 74.35 & 43.62 \\
\hline
\end{tabular}

Values are presented as percentage.

$\mathrm{DH}$, degree of hydrolysis.

${ }^{1)}$ Enzymatic hydrolysis was carried out for $3 \mathrm{~h}$ by two enzymes cotreatment. Reaction conditions: $0.5 \%$ Flavourzyme, different concentration of Viscozyme, $50^{\circ} \mathrm{C}$ and $\mathrm{pH} 5.5$. Enzyme dosage was based on solid content. 
for maximizing substrate degradation.

\section{The cultivation of lactic acid bacteria on enzymati- cally hydrolyzed RGR}

To verify the utility of ERGR as a microbial culture medium, changes in cell growth and the $\mathrm{pH}$ and titratable acidity of ERGR and RGR suspensions fermented with $L$. mesenteroides KACC 91459P were monitored (Fig. 2). For the RGR medium, while the $\mathrm{pH}$ of the fermented broth decreased from 6.0 to 4.08 after $6 \mathrm{~h}$ of fermentation, its titratable acidity increased from $0.05 \%$ to $0.414 \%$ and was thereafter maintained at around $0.43 \%$ for a further $18 \mathrm{~h}$. For the ERGR medium, the $\mathrm{pH}$ similarly decreased (from 6.0 to 3.91 after $6 \mathrm{~h}$ of fermentation, and then more gradually to 3.69 at $24 \mathrm{~h}$ ), while its titratable acidity increased hyperbolically from $0.05 \%$ to $0.846 \%$ at $24 \mathrm{~h}$. The ERGR and RGR media were initially inoculated with approximately $6-8 \times 10^{7} \mathrm{CFU} / \mathrm{g}$ of L. mesenteroides KACC 91459P. After cultivation for 6 $\mathrm{h}$, the viable cell counts for both cultures had increased to $1.3 \times 10^{9} \mathrm{CFU} / \mathrm{g}$. However, while the viable cell population decreased dramatically to $2.4 \times 10^{6} \mathrm{CFU} / \mathrm{g}$ for the RGR culture, it was maintained during $24 \mathrm{~h}$ of fermentation in ERGR medium. These results are superior to those obtained in previous studies involving lactic acid bacteria cultivated in a mixture of milk and cultured ginseng extract [24] or MRS medium containing ginseng powder [25]. When Lactobacillus plantarum (L. plantarum) MG208 was cultivated with MRS medium containing 5\% red ginseng powder, the viable cell counts,
$\mathrm{pH}$, and titratable acidity of the broth changed to $4.7 \times 10^{8}$ $\mathrm{CFU} / \mathrm{mL}, 3.73$, and $0.59 \%$, respectively, after $24 \mathrm{~h}$ of fermentation [25]. Although L. plantarum MG208 differs from $L$. mesenteroides KACC 91459P, the fermentation characteristics of lactic acid bacteria were superior in ERGR medium than in MRS medium containing 5\% red ginseng powder. These data suggest that the ERGR medium on its own contains sufficient nutrients to support bacterial growth and can be utilized as a microbial growth medium without the addition of nutritional supplements. Previous studies have investigated the potential of adding RGR to existing fermentation media as a nutritional supplement $[7,26]$. To the best of knowledge, the present study is the first to explore the possibility of using RGR as a non-supplemented microbial cultivation medium.

\section{REFERENCES}

1. Attele AS, Wu JA, Yuan CS. Ginseng pharmacology: multiple constituents and multiple actions. Biochem Pharmacol 1999;58:1685-1693.

2. Park JD. Recent studies on the chemical constituents of Korean ginseng (Panax ginseng C. A. Meyer). Korean J Ginseng Sci 1996;20:389-415.

3. Ko SK, Lee CR, Choi YE, Im BO, Sung JH, Yoon KR. Analysis of ginsenosides of white and red ginseng concentrates. Korean J Food Sci Technol 2003;35:536-539.

4. Sung HS, Yoon SK, Kim WJ, Yang CB. Relationship between chemical components and their yields of red gin-

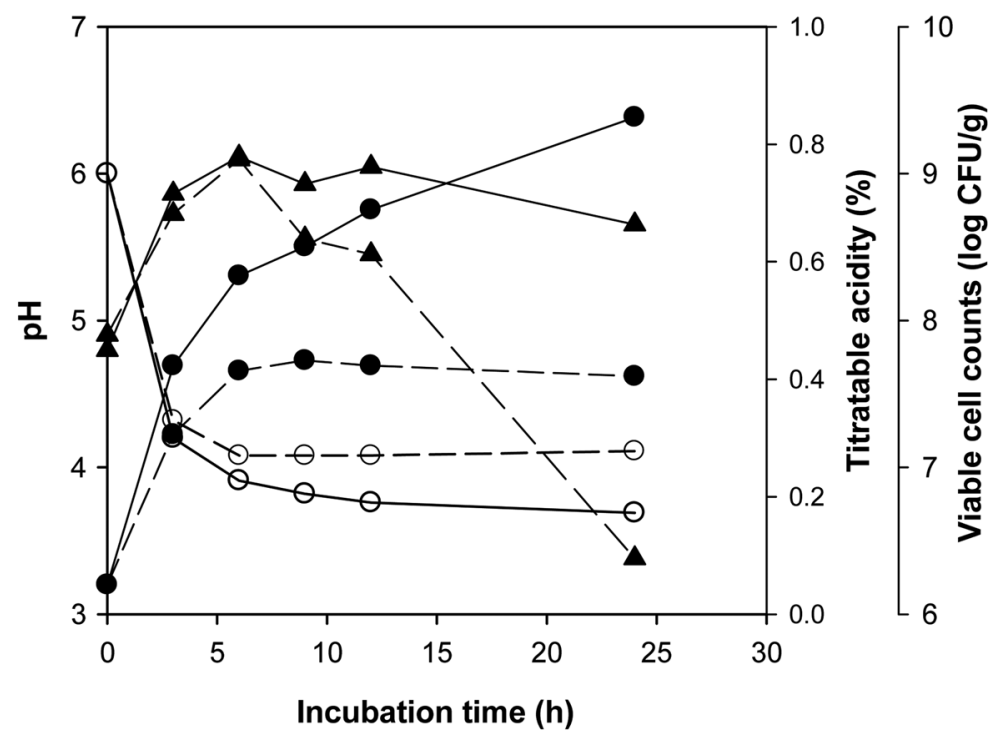

Fig. 2. Changes in the growth $(\boldsymbol{\Delta})$ of Leuconostoc mesenteroides KACC 91459P and in the titratable acidity $(\bullet)$ and $\mathrm{pH}(\circ)$ of the red ginseng residue medium (broken line) and enzymatically hydrolyzed red ginseng residue medium (solid line) during lactic acid fermentation at $30^{\circ} \mathrm{C}$. 
seng extract extracted by various extracting conditions. Korean J Ginseng Sci 1985;9:170-178.

5. Yoo B, Choi YH, Lee SY. Effect of extracting condition on rheological behaviors of Korean red ginseng extract. Food Sci Biotechnol 2003;12:88-91.

6. Lee SD, Yoo G, Chae HJ, In MJ, Oh NS, Hwang YK, Hwang WI, Kim DC. Lipid-soluble extracts as the main source of anticancer activity in ginseng and ginseng marc. J Am Oil Chem Soc 2009;86:1065-1071.

7. Kim SD, Do JH, Lee KS, Sung HS. Effect of ginseng residue extract on yeast growth. Korean J Ginseng Sci 1986;10:1-10.

8. Lee JW, Do JH. Extraction condition of acdic polysaccharide from Korean red ginseng marc. J Ginseng Res 2002;26:202-205.

9. Yoo G, Lee SD, In MJ, Hwang WI, Lee KS, Lee ES, Kim DC, Chae HJ. An alternative sequential extraction process for maximal utilization of bioactive components from Korean red ginseng. Korean J Chem Eng 2009;26:10941097.

10. Bae EA, Park SY, Kim DH. Constitutive beta-glucosidases hydrolyzing ginsenoside $\mathrm{Rb}_{1}$ and $\mathrm{Rb}_{2}$ from human intestinal bacteria. Biol Pharm Bull 2000;23:1481-1485.

11. Ko SK, Cho OS, Bae HM, Yang BW, Im B, Hahm YT, Kim KN, Cho SH, Kim JY, Chung SH, Lee BY. Changes in ginsenoside composition of white ginseng by fermentation. Food Sci Biotechnol 2009; 18:253-256.

12. Kim HJ, Chae IG, Lee SG, Jeong HJ, Lee EJ, Lee IS. Effects of fermented red ginseng extracts on hyperglycemia in streptozotocin-induced diabetic rats. J Ginseng Res 2010;34:104-112.

13. Cho K, Woo HJ, Lee IS, Lee JW, Cho YC, Lee IN, Chae HJ. Optimization of enzymatic pretreatment for the production of fermented ginseng using leaves, stems and roots of ginseng. J Ginseng Res 2010;34:68-75.

14. In MJ, Kim HM, Jin HJ, Kim DC, Oh NS, Chae HJ. Production of a fermented Korean pear puree using a new strain Leuconostoc mesenteroides KACC 91495P isolated from Kimchi. J Appl Biol Chem 2010;53:51-55.
15. Korea Foods Industry Association. Food code. Seoul: Moonyoungsa, 2009.

16. Dubois M, Gilles KA, Hamilton JK, Rebers PA, Smith F. Colorimetric method for determination of sugars and related substances. Anal Chem 1956;28:350-356.

17. Miller GL. Use of dinitrosalicylic acid reagent for determination of reducing sugar. Anal Chem 1959;31:426-428.

18. Chae HJ, In MJ, Lee JD. Production of a protein supplement from soymilk residues by combined use of enzymes and microorganisms. Agric Chem Biotechnol 1998;41:7377.

19. Chae HJ, Han MS, In MJ. Study on utilization of vegetable by-product from food processing by enzyme treatment. J Korean Soc Appl Biol Chem 2004;47:146-148.

21. Chae HJ, Joo H, In MJ. Utilization of brewer's yeast cells for the production of food-grade yeast extract. Part 1: effects of different enzymatic treatments on solid and protein recovery and flavor characteristics. Bioresour Technol 2001;76:253-258.

22. In MJ, Chae HJ, Oh NS. Process development for hemeenriched peptide by enzymatic hydrolysis of hemoglobin. Bioresour Technol 2002;84:63-68.

22. In MJ, Jang JE, Kim DH. Enhancing extraction yield of chlorella extract by enzyme treatment. J Appl Biol Chem 2007;50:132-135.

23. In MJ, Choi JH, Kim S, Chae HJ, Kim DH. Enhanced extraction of astaxanthin from Haematococcus pluvialis using enzyme treatments. J Korean Soc Appl Biol Chem 2008;51:247-249.

24. Lee IS, Paek KY. Preparation and quality characteristics of yogurt added with cultured ginseng. Korean J Food Sci Technol 2003;35:235-241.

25. Park S, Kim DH, Paek NS, Kim SS. Preparation and quality characteristics of the fermentation product of ginseng by lactic acid bacteria. J Ginseng Res 2006;30:88-94.

26. Kim SD, Do JH, Lee JC. Effect of red ginseng residue on various enzyme production of alcohol fermentation koji. Korean J Ginseng Sci 1982;6:131-137. 